\title{
Beyond ethical approval: fostering ethical research practices within inter-sectoral research projects involving academic and NGO sector partners
}

\author{
Ronan McDermott ${ }^{1 *}$ D, Pat Gibbons ${ }^{1}$, Desire Mpanje', Sinéad McGrath², Anne Markey ${ }^{3}$, Pablo Cortés Ferrandez ${ }^{4}$, \\ Dini Haryati ${ }^{5}$ and Nur Azizah ${ }^{5}$
}

\begin{abstract}
While research and innovation collaborations between NGOs and academic organisations can create considerable synergies with positive effects for the humanitarian sector, the inter-sectoral nature of such collaborations can generate challenges due to the varying mandates, objectives and ways of working of the organisations involved. By drawing on the experiences of a 4-year project involving a consortium of academic and NGO partners, this paper outlines three broad and inter-related ethical challenges that such projects can encounter and how they can be practically negotiated. Firstly, how are the knowledge-generation requirements of such projects addressed without engaging in the mere extraction of data from participants? Secondly, how are potential risks to participants arising from their participation balanced with the need to include their voices within the research project? Finally, how are the formal requirements laid down by institutional review committees, primarily within academic organisations, to be adhered to within field contexts in which there are well-established expectations and ways of working on the part of NGO partners and beneficiaries? While these dilemmas are merely illustrative of the potential ethical dilemmas that inter-sectoral collaboration might encounter, the paper highlights that ethical dilemmas ought to be addressed reflexively by all stakeholders in order to facilitate improved collaboration and, ultimately, better quality, more relevant and more ethically informed research.
\end{abstract}

Keywords: Research ethics, Research methods, Partnership, Localisation

\section{Introduction}

In recent years, the ethics of research undertaken by and in collaboration with humanitarian actors has been increasingly discussed. These discussions are taking place against the backdrop of increased health and social science research as a result of the drive towards evidence-based humanitarian programming (Falb et al. 2019). A range of governance approaches from guidelines to institutional ethical review processes have been developed which have been tailored to various stakeholders within humanitarian research, including non-governmental organisations (NGOs) (Schopper et al. 2015), funding agencies, and the

\footnotetext{
* Correspondence: ronan.mcdermott@ucd.ie

${ }^{1}$ Centre for Humanitarian Action, School of Agriculture and Food Science,

University College Dublin, Belfield, Dublin 4, Ireland

Full list of author information is available at the end of the article
}

academic sector (Statement of Commitments from $\mathrm{Hu}$ manitarian Scholars at World Humanitarian Summit 2016; Van Bavel et al. 2016). Sector-wide initiatives and discussions have identified how ethics and values are implicated in humanitarian research, i.e. the aims of such research, as well as how the research is undertaken and its impact on intended beneficiaries. ${ }^{1}$ They have largely centred around how individual organisations and humanitarian professionals address ethical dilemmas that arise during the research process. This paper contributes to the discussion by providing a commentary on the engagement with ethical considerations arising within a project by

\footnotetext{
${ }^{1}$ Such discussions range from those initiated by Evidence Aid (http:// www.evidenceaid.org/ethics-and-evidence/) to Power, Prestige \& Forgotten Values: A Disaster Studies Manifesto (https://www.ipetitions. $\mathrm{com} /$ petition/power-prestige-forgotten-values-a-disaster).
} 
virtue of it being undertaken by a multi-sectoral consortium composed of academic organisations, NGOs and a private sector organisation. Particular ethical considerations arise in such projects due to the varying mandates, objectives and ways of working of the organisations involved. The ethical dilemmas that arise and how they are practically negotiated are the focus of this commentary.

The Preparedness and Resilience to address Urban Vulnerability (PRUV) project is inter-disciplinary, intersectoral and international in nature, focusing on highly diverse urban and peri-urban informal settings in Soacha, Colombia; Jakarta, Indonesia; and Nairobi, Kenya. ${ }^{2}$ Funded by the European Union's Horizon 2020 programme and coordinated by a university with rigorous research ethics protocols, there are a number of stringent ethical requirements with which the project needed to comply. In addition to meeting the requirements of academic and grant agency review committees, the project was also concerned with maximising the utility of the research to generate findings that are directly relevant to the urban field sites as well as similar urban settings globally. Using a mixed-methods approach, over 650 people participated in a comparative household livelihood survey and a range of participatory qualitative methods. Particular attention was given to the coping mechanisms employed by households in stressful situations. While no judgements were made on the coping mechanisms employed by households in the household study, community representatives were requested to indicate envisaged local preferred options to deal with ongoing and recurring socks and stresses. The qualitative methods provided the opportunity to interrogate culturally perceived negative coping strategies in a more anonymised/generalised way.

In undertaking research projects of this kind, a certain tension is encountered between what Guillemin and Gillam (2004) term procedural ethics on the one hand and ethics in practice on the other hand. In other words, how are the formal ethical precepts translated practically within complex and potentially unforeseeable interactions between and among those engaged in research. Procedural ethics within the social sciences have been informed by initiatives such as the Nuremburg Code and the Declaration of Helsinki (Hugman et al. 2011). They have been fostered and promoted by research institutions such as universities and medical facilities. However, the requirements laid down by research ethics

\footnotetext{
${ }^{2}$ The research was conducted as part of the Preparedness and Resilience to address Urban Vulnerability (PRUV) project, a EuropeanUnion funded Horizon 2020 project, which aims to inform the pressing need to reshape how humanitarian action and development aid is undertaken in urban areas in order to address the challenge posed by urban vulnerability. More details can be found on the project website pruv.ucd.ie.
}

committees need to be reconciled with the practicalities, complexities and singularities of more or less unforeseeable human and institutional interactions that are inherent to social research, particularly with vulnerable groups in research related to humanitarian action (Redwood and Todres 2006).

A solution to this tension identified by Guillemin and Gillam (2004) is to engage in a form of reflexivity with respect to ethical issues arising during the course of research. Reflexivity is a concept familiar to qualitative researchers and involves critical reflection by the researcher on his/her engagement within the research process. However, how is it to be achieved in a context where there are multiple lines of accountability between the researcher and participants, ultimate beneficiaries of research, funding agencies, ethics review committees and partner organisations engaged in research? This paper illustrates, on the basis of three dilemmas encountered during the PRUV project, how such reflexivity may be conducted in the context of a research partnership between academic and NGO actors engaging with what would be considered vulnerable groups. Each of these dilemmas is addressed in turn within the paper. The first dilemma addressed concerns the role of the affected population in the research process while staying true to the principles of social research. How can important knowledge generation requirements within research projects (including the identification and documentation of good practice, development of policy recommendations for advocacy purposes, and the publication of findings to contribute to knowledge) be met while avoiding the mere extraction of data from participants living in vulnerable contexts? The second dilemma concerns the issue of protecting the anonymity of study participants to ensure that there would be no reprisals resulting from engagement in the study. In other words, how are the benefits of including participants' voices within a research project to be balanced with the risks to reputation or physical security that might accrue to such persons arising from their participation? Finally, the third dilemma concerns the lack of agreement on the values of research ethics from disparate sectoral interests. How are formal ethical requirements demanded of ethical review committees are adhered to within research projects conducted in collaboration with partner organisations and communities in diverse economic and cultural contexts in which there are well-established expectations concerning how research is to be conducted? While none of the above dilemmas is novel, the paper aims to illuminate practically how they were negotiated throughout the course of a project involving organisations with different mandates 
(Guillemin \& Gillam 2004; Block et al. 2012). The implications for multi-organisational research studies, the process of ethical review of research projects and for research practice more broadly are then drawn out.

\section{Engaging affected populations meaningfully in the research process while maintaining the pursuit of project objectives}

A dilemma encountered within the project concerned the need to meet project objectives relating to knowledge generation while avoiding the mere extraction of data from participants within the project. The objective of promoting the localisation of research projects and inclusivity within research projects has been increasingly prominent within the fields of humanitarian action and disaster management (Gaillard 2019). Commitment No. 4 of humanitarian scholars at the 2016 World Humanitarian Summit called for the "localisation of research projects within the regions and communities affected by emergencies" (Statement of Commitments from $\mathrm{Hu}$ manitarian Scholars at World Humanitarian Summit 2016). Similarly, the Disaster Studies Manifesto, promulgated in 2019 by a range of disaster management researchers, calls in Section 3.6 for the deployment of "methods that enable and encourage local people to lead and critique enquiry and local scientific endeavours that provide maximum benefit to local researchers and the people who are the subjects of research." ${ }^{3}$ More broadly, the ethical principle of beneficence dictates that research undertaken ought to be beneficial to the persons concerned, not merely to the research team and/or the generation of knowledge (Constantin 2018; Ritchie et al. 2003). The twin objective of being beneficial to participants and local researchers has methodological implications for the actors involved in guiding and conducting the research. In this view, the ethical dimension permeates every aspect of methodology (Van Duijn and Hilhorst 2019).

In terms of the research methods deployed, the literature makes a strong argument for the value of participatory research as being:

...rooted in principles of justice and democracy...an inclusive, collaborative approach to research defined both by participation and a determination to produce knowledge in the interest of social change. (Torre et al. 2015: 540)

The PRUV project has occasionally encountered the familiar refrain from participants concerning the lack of feedback of results by research teams that had previously

${ }^{3}$ Disaster Studies Manifesto, Section 3.6 https://www.ipetitions.com/ petition/power-prestige-forgotten-values-a-disaster engaged in the same locale. For example, the coordinator of a community-based organisation active in one of the selected PRUV localities claimed during an interview conducted on 25 May 2016 that:research projects have to take into account the vulnerability of the population and offer them something after they participate; they recount their lives and they open wounds.

Participatory research engages a wide range of data collection tools; two commonly advocated tools are transect walks and mapping exercises. Participatory methodology is considered to best contribute to an open dialogue, which would do less harm to the community, by providing it with tools that are useful in assessing their own progress and development.

This study developed an Urban Vulnerability Walk (UVW) for use in Indonesia and Colombia, which was adapted from Plan International's Girls' Safety Walk in Kenya. It was adapted to local considerations in each of the cities included within the PRUV project. The method yielded detailed information about how different groups of women, men, adolescent girls and boys view specific sites within informal urban settlements in the three case study cities. As an inherent part of the tool, these groups formulated separate recommendations for making improvements within the communities, and these recommendations can be used-in conjunction with the rest of the qualitative and quantitative data-to inform the community on their spatial vulnerabilities within urban areas and safe, transformative spaces of resilience within these communities. Particularly notable in the case of Indonesia was that at the beginning of the study participants assumed that the environment they lived in did not face challenges related to safety and security; after the study was conducted, they highlighted a range of environmental risks to their safety and security.

The Urban Vulnerability Walk (UVW) was paired with a social cartography, which is a mapping exercise aimed at obtaining an understanding of the risks, vulnerabilities and social assets within a community. The two methods were paired so as to use the second as a 'reflective' exercise for the first. The approaches to the deployment of this method varied across the three case studies to suit the realities of the local communities. In the Colombian case, both exercises were conducted months apart, with the mapping exercise undertaken in June 2017 and the walks undertaken in January and March 2018, as the latter focused especially on gender specificities. In both Jakarta and Nairobi, the exercises were conducted on the same day, which allowed participants to articulate more clearly their perceptions of the reality of the setting. In Jakarta conducting the mapping exercise after the urban vulnerability walk served to highlight risks 
and vulnerabilities that were not immediately apparent to the residents of the area. In Nairobi, the mapping exercise served as a useful springboard for discussion. Feedback from researchers found that it would have been particularly useful to have two mapping exercises, one before and one after, to measure potential shifts in awareness levels based on community perceptions. All three cases found, however, that the relationship between the social cartography and UVW created (1) a positive environment for open, relaxed, and inclusive discussion of somewhat difficult topics; (2) an awareness of urban vulnerabilities that had not been considered by participants prior to the study; and (3) a clear 'mapping' of where opportunities for change existed within these communities. The participatory nature of these exercises allowed communities not only to create visual maps of their communities but mental maps of what they would like these to look like and thus allowed them to focus on future action which need to be taken to achieve this. In so doing, a participatory action research approach was adopted (Kemmis and McTaggart 2005). This example highlights that the selection and design of participatory methods in collaboration with local actors has an important role in providing direct benefit to research participants and wider communities in emergency contexts as well as deeper insight into the phenomena under study, putting the community's reality at the forefront of the research (Chambers 1997). While such enhanced engagement might enhance the utility of findings to local communities, it may well come at a cost in terms of generalisability. This highlights the potential tensions between academic organisations with their foremost concern for knowledge generation vis-à-vis NGOs with their foremost concern for the communities within which they work.

In terms of the engagement of local actors in the design and conduct of research projects, the ethical rationale for increased localisation and inclusivity contains both utilitarian and deontological dimensions. From a utilitarian perspective, research projects can benefit from "insiders" insofar as they tend to be better positioned to ask meaningful questions, understand non-verbal cues, have much easier access to the community under study and of course have a greater understanding of the cultural context. However, along with such advantages may come the possibility of bias and a cultural inability to ask certain questions which may be crucial to the study (Merriam et al. 2001). Participants can have concerns over confidentiality when insiders are involved in the research, particularly when discussing cultural taboos Liamputtong (2008). "Outsiders", on the other hand, are thought to have difficulty in understanding the cultural significance of certain expressions, may be unable to read body language and may need much longer to build trust. Advantages are that the outsider may be less biased, non-aligned and able to gather more objective information. This view of the insider/outsider phenomenon may be too simplistic in that it does not take into consideration important factors such as power, positionality and representation (Dwyer and Buckle 2009). For example, a cultural 'insider' from a different social background, class and race to the community under study may have disadvantage over the outsider as, although the researcher may be from the same country, her daily reality will be very different, thus making trust harder to build. In fact, there is no solution to the insider/outsider dilemma, and the best that can be done, according to Liamputtong (ibid. 238), is "to reflect upon what gives the most in every single situation". Set against this utilitarian approach to the insider-outsider approach is the intrinsic value placed on localisation, collaboration and inclusivity within the design and implementation of research projects as well as the communication of research findings.

Within each period of data collection, consideration was given to whether it was preferable to have an insider or an outsider conduct the research. The approach to the composition of the research team working directly with research participants varied across case studies with important implications in terms of joint ownership of the process. In the case of Jakarta, the research was solely conducted by Indonesian researchers due to political sensitivities arising from approaching elections at the time of data collection. In Nairobi and Soacha, a mix of non-Kenyans and non-Colombians collaborated with Kenyan and Colombian nationals respectively. In the three case study sites, where a choice in terms of the composition of the particular research team working directly with participants was available, the project generally was guided by partner NGOs working in the locality and the key informants, which included local government officials, social workers and teachers. This highlights the importance of stakeholder engagement in designing and implementing research projects. Where it is feasible to include affected populations within the design and implementation of research, the distinction between the researcher and the researched is further blurred (Hugman et al. 2011). This would also serve to ease the dilemma that might otherwise arise between the pursuit of research project objectives and producing direct benefits to participants.

\section{Minimising potential risk of harm to participants while encouraging participation}

The second dilemma that the project encountered was how to balance the risk posed to research participants arising from their inclusion in the study with the risks of their non-participation. Much research in humanitarian 
settings is necessarily conducted with persons who are considered vulnerable or who are considered to be at higher risk of harm or wrong (Hugman et al. 2011: 656). The inclusion of such persons' voices is essential in order to advance knowledge within the sector. However, it is also understood that such persons are to be especially protected within the research process (BrackenRoche et al. 2017). Protection safeguards are particularly necessary in the case where the mere inclusion of participants within a research project comes at a potential cost to the reputation, personal security or even lives of those being seen to engage with a research team. This dilemma crystallised within the project in relation to informed consent. Informed consent is generally a requirement of institutional ethical review processes involving human subjects (Hugman et al. 2011: 658). ${ }^{4}$

The nature of the research, its risks and benefits to participants, if any, must be explained from the outset. This was undertaken in collaboration with the NGO members of the project, using key informants, who were respected by and familiar with the community. The role of key informants as members of the community who understand the relevant culture and structures was an essential part of the planning before the research was conducted, as researchers and key informants discussed issues related to cultural contexts and norms, as well as helped in identifying suitable participants. Researchers in Jakarta, Nairobi and Soacha relied on community leaders as defined and identified by the NGO members of the consortium. Key informants were also crucial in providing information in general to participants about the study that would be conducted, creating a trusting relationship among researchers and participants. Researchers were therefore able to give a more detailed explanation of the aims of the study prior to it being conducted, and participants found it easier to understand the aims of the research. Once participants felt familiar with the research, they were able to provide a record of their informed consent to researchers. Despite this approach, challenges to obtaining informed consent persisted. In Soacha, Colombia, it proved to be challenging to recruit study participants in relation to the qualitative methods deployed due to limited trust between the people living in the informal settlements and external actors. Most of the people who declined to participate in the study cited doubts about how the information they might provide would be handled and

\footnotetext{
${ }^{4} \mathrm{An}$ exception is where deception is a part of the research design in which case participants must consent to participate but are unaware that deception is a feature of their participation. In such circumstances, it is permissible to not disclose every aspect of participation within a research project before data collection. However, full debriefing and retrospective full consent is the recommended best practice.
}

the potential for serious consequences for them, despite assurances that no personal data would be collected. Others who had the same concern over being identified were nonetheless willing to participate in the study. However, they refused to sign or otherwise identify themselves on the basis of consent forms or provide an audio or visual record of informed consent. The project was thereby challenged in terms of how to address participants eager to participate but reluctant to provide recorded informed consent. In other words, how can the need to comply with formal informed consent requirements be reconciled with the ethical imperative to include marginal and vulnerable voices? Ultimately, the project adhered to formal ethical requirements and excluded such persons' data within the analysis phase, thus losing potentially important data as well as the input of people potentially of most relevance to the study.

The benefit of a signed consent form is that "it is explicit, clear, can be tracked and scrutinized and in the event of a complaint can provide the basis for structured accountability" (Hugman et al. 2011: 660). In any case, a signed consent form or audio of a participant declaring consent does not directly equate to informed consent, which is ultimately is the interpersonal process between research and participant whereby the study is explained, and the researcher makes a free decision to participate on his or her own terms (Guillemin and Gillam 2004). Furthermore, where the requirement of a signed consent form thwarts the engagement of hard-to-reach participants within the research process, the value of requiring documented informed consent arguably further recedes. While informed consent is a non-negotiable, how this is to be achieved should be subject to flexibility and sufficiently consider other competing ethical demands. The tension between formal ethical requirements and field realities links with the third dilemma, which is outlined in the following section.

\section{Reconciling ethical standards with expectations of NGO partners and prospective participants}

A third dilemma arose within the consortium stemming from the composition of the consortium. University members, with strict institutional research ethical review processes, have engaged with NGOs for many years, if not decades and have established norms of engagement with affected communities. While the synergies emerging from the interaction of organisations from different sectors have been on the whole undoubtedly beneficial overall to the research project, the ethical requirements imposed by ethical review boards on the conduct of the research project had to be reconciled with the existing ways of working and relationships established within the field study sites. An example of this centres around the compensation or reimbursement of participants for their 
time and engagement within the research project. Compensation of participants for their time needs to be justified within the research process and needs to be carefully considered in the context of informed consent (Roche et al. 2013). Two competing considerations arise when considering the compensation of vulnerable persons. On the one hand, it is important to acknowledge and express gratitude to participants for their time and input. Appropriate compensation is also instrumental in promoting recruitment of participants. On the other hand, compensation must not be so great within the economic or cultural context that it overrides the consent of the participant. It can be challenging to negotiate this balance in resource-poor settings and in the context of the variety of established NGO practices concerning the reimbursement of research participants/project beneficiaries. Compensation or reimbursement of participants is also relevant to the general efficacy of the research, both in terms of the number and characteristics of recruited participants as well as the quality of participation within the research process (Slomka et al. 2007: 1408). The literature identifies the need to consider the potential crowding-out effect that might arise due to erosion of the gift relationship identified by Richard Titmuss in his 1970 work, The Gift Relationship (Titmuss 2018). While this effect may be less relevant in resourcepoor contexts, concern for free and informed consent to participate may sharpen (Zutlevics 2016: 146). Consideration ought to be given to the effect inducements have on recruitment, both in terms of the numbers of participants recruited and the characteristics of those recruited, as well as on the manner in which participants engage within the research. The provision of inducements also has implications for expectations of participants within future research projects. There is some contestation in the literature as to the effect that the offer of financial compensation has on participation.

When conducting the study across the three case studies, the research teams encountered a variety of expectations around compensation. A positive experience from Jakarta involved the researcher and key informant discussing compensation that was appropriate and yet did not cause negative social impacts. Information about compensation from the key informants was used as the basis for providing appropriate compensation that can be provided to participants. In Soacha, participants received no compensation and the NGO partner recommended not to provide any form of direct compensation to participants as this would set the wrong precedent. However, motivating participants to provide their time and input to the researchers was a challenge as a result. On numerous occasions, participants reminded the researchers that they needed to spend no longer than 30 min during interviews due to the need to attend to other activities. On other occasions, participants would withdraw without notice before the agreed timeframe had elapsed. One of the participants confided to the researchers after the interview that he/she felt the need to withdraw because he/she did not see any benefit from participating in studies as researchers come, collect information and leave with no direct benefit whatsoever to those who participated in interviews.

In Nairobi, participants were provided with compensation to the value of 100 to 500 Kenyan shillings (approximately $€ 1.00$ to $€ 5.00$ ). This was provided in the form of refreshments commonly involving bread and milk as recommended by the NGO partner. However, some participants demanded that they be provided compensation in the form of cash and not bread and milk. Unlike in Soacha where it was challenging to find participants, in Nairobi many participants were willing to participate. Nevertheless, it subsequently became clear that there was a hidden motivation related to the compensation available. Some participants indicated that they would participate only if they were to be paid not the refreshments but a fee for participating in the study. They cited the same reason as not seeing or receiving direct benefits from the many research activities that had been undertaken in the locality. They would prefer to enjoy the benefits of participating in the study instantly than wait until the results are shared and policies recommended since this would mean someone else benefiting other than themselves.

In Jakarta, the participants were provided with a small gift at the end of each method conducted. The provision of the small gift was not flagged to participants in advance, although it must be presumed that details of the provision of a small gift being available would have been circulated within the communities concerned. An initial proposal had been to provide compensation in monetary terms of up to 50,000 Rupiah (approximately €4.50). However, data collection coincided with electioneering in the run up to presidential elections. The NGO partner recommended provision of gifts in the form of souvenirs instead of cash to avoid raising political suspicions in the locality, which could in turn jeopardise the data collection process and the reputation of the NGO partner.

The diversity of expectations across the different cities involved in the study concerning reimbursement is quite striking. This may reflect to some extent cultural differences, but it also undoubtedly reflects levels of trust in agencies from outside the localities. It is difficult to identify how the different approaches to reimbursement had an impact on the characteristics and numbers of participants recruited. However, it can be argued that those who participated in Soacha and Nairobi were more altruistic than the general population. The constraints on time, particularly in Soacha, highlight how reimbursement can 
influence the quality of research findings and the limitations of reliance solely on altruistic motivation of participants in the absence of the guarantee of direct benefits from the research conducted. Ultimately, it is important to address carefully the motivations for participation in research projects. Reimbursement of participants must be carefully considered in light of informed consent and respecting existing ways of working, including relationships between NGOs and affected communities. However, the potential repercussions for the recruitment and disposition of participants need to be also considered. The variegated approach to reimbursement across context emerged over time through engagement with NGO partners and prospective participants, highlighting yet again the importance of the distinction between procedural ethics and ethics in practice.

\section{Conclusion}

This paper can be considered a form of reflexivity with respect to research practice relating to humanitarian action. It highlights that ethics permeate the entire research enterprise as recent initiatives such as the WHS and the Disaster Studies Manifesto identify. The PRUV research project is being implemented by a consortium of several academic, NGO and private sector participants, and the paper identifies how approaches to addressing ethical dilemmas can be addressed collectively. The number and diversity of the consortium partners necessitated ongoing discussion throughout the project concerning the ethical dimension of the project's activities. The different organisations naturally have different priorities in terms of mandate, objectives and ways of working leading to implications in terms of the design and implementation of methods, the preferred composition of teams of researchers as well as compliance with formal ethical requirements in contexts of established ways of working and field realities. This has important implications in terms of the approach to obtaining informed consent, minimising risk and inconvenience to participants as well as the promotion of benefit-sharing within the research process. Perhaps paradoxically, the project has demonstrated that adherence to ethical standards across different contexts requires a thorough understanding of context that emerges through a constant deliberation with the relevant stakeholders. It has also highlighted how ethics permeates all methodological dimensions of the project from the design stage and the importance of the leadership of affected populations through to the dissemination stage and the importance of impactful, direct benefits. The need for procedural ethics to be complemented by ethics in practice is necessary particularly in humanitarian research due to the epistemological nature of a lot of research undertaken and the often-extreme material and security conditions in which humanitarian research is conducted, generating ethical complexities that cannot be foreseen.

Within research projects, ethics review committees and other similar bodies are indispensable. While the formal ethical review process takes time and resources, particularly where multiple approvals are required and where funding bodies require reporting, they provide an important check-list and help to in-build essential research practices (Guillemin and Gillam 2004). Through their important gate-keeping role for research projects, they also contribute to instilling ethical sensitivity within the research community. However, the ethical responsibilities of researchers cannot end with receipt of formal approval from research ethics committees ahead of the beginning of a research project. The important ethical moments encountered in research of the nature outlined in this paper cannot always be contemplated or regulated by ethics committees. There needs to be greater engagement in deliberation and greater opportunities for the maintenance of approvals despite a study being redesigned as a result of engagement with key stakeholders, including research participants. There is a need for a greater ongoing reflexivity on the part of different sectors concerning expectations during the course of the research process. More generally, there is a need for an improved reflexivity by, and dialogue between, researchers, regulators, funding bodies and ethics committees that sufficiently consider disciplinary differences, including the particular challenges posed by applied qualitative social science research. This is necessary if we are to adhere to the commitments made by scholars at the World Humanitarian Summit, within the Disaster Studies Manifesto and as part of similar initiatives. Ultimately, academics and humanitarian agencies in partnership for research purposes need to better understand each other's missions as well as each other's institutional constraints and opportunities in order to facilitate and safeguard ethical and impactful research.

\section{Abbreviations}

NGO: Non-governmental organisation; PRUV: Preparedness and Resilience to address Urban Vulnerabilities; WHS: World Humanitarian Summit

\section{Authors' contributions}

RMcD contributed to the overall concept and structuring of the paper writing the introduction and conclusion and assisting with the overall writing process throughout. PG contributed to the paper by highlighting the overall utility of the paper to collaborations involving actors from the academic and NGO sectors. He also helped to clarify the key dilemmas and acted as Coordinator of the PRUV project. DM contributed to the paper in relation to the practical challenges in obtaining informed consent and providing reimbursement of research participants. SMcG contributed to the development of the novel methods and the discussion of the inclusivity of research projects. AM contributed to the report concerning general research ethics requirements and standards. PCF contributed to the section of the report concerning the first dilemma on the basis of his field research within the PRUV project. DH and NA contributed to identifying the practical utility of the research methods deployed within the PRUV project. All authors read and approved the final manuscript. 


\section{Funding}

This article has been written as part of the Preparedness and Resilience to address Urban Vulnerabilities (PRUV) project. The project has received funding from the European Union's Horizon 2020 research and innovation programme under the Marie Skłodowska-Curie grant agreement no. 691060.

\section{Availability of data and materials}

The article is based on the experiences of the authors together with reflection on relevant scholarly and grey literature referenced in the bibliography.

\section{Competing interests}

The authors declare that they have no competing interests.

\section{Author details}

${ }^{1}$ Centre for Humanitarian Action, School of Agriculture and Food Science, University College Dublin, Belfield, Dublin 4, Ireland. ${ }^{2}$ School of Politics and International Relations, University College Dublin, Dublin, Ireland. ${ }^{3}$ School of Agriculture and Food Science, University College Dublin, Dublin, Ireland. ${ }^{4}$ Pedro Arrupe Institute of Human Rights, University of Deusto, Bilbao, Spain. ${ }^{5}$ Cipta Foundation, Jakarta, Indonesia.

\section{Received: 18 June 2019 Accepted: 9 October 2019}

Published online: 11 November 2019

\section{References}

Block, K., Warr, D., Gibbs, L. and Riggs, E., (2012) Addressing ethical and methodological challenges in research with refugee-background young people: reflections from the field. Journal of Refugee Studies, 26(1), pp.69-87.

Bracken-Roche, D., Bell, E., Macdonald, M.E. and Racine, E., (2017) The concept of 'vulnerability'in research ethics: an in-depth analysis of policies and guidelines. Health research policy and systems, 15(1), p. 8.

Chambers R (1997) Whose reality counts, vol 25. Intermediate technology publications, London

Constantin V (2018) Human subject research: international and regional human rights standards. Health Hum Rights 20(2):137-148

Dwyer SC, Buckle JL (2009) The space between: on being an insider-outsider in qualitative research. Int J Qual Methods 8(1):54-63

Falb K, Laird B, Ratnayake R, Rodrigues K, Annan J (2019) The ethical contours of research in crisis settings: five practical considerations for academic institutional review boards and researchers. Disasters published online 22 August 2019. https://doi.org/10.1111/disa.12398

Gaillard JC (2019) Disaster studies inside out. Disasters 43:7-17

Guillemin M, Gillam L (2004) Ethics, reflexivity, and "ethically important moments" in research. Qual Inq 10(2):261-280

Hugman R, Bartolomei L, Pittaway E (2011) Human agency and the meaning of informed consent: reflections on research with refugees. J Refug Stud 24(4): 655-671

Kemmis S, McTaggart R (2005) Participatory action research: communicative action and the public sphere. In: Denzin NK, Lincoln YS (eds) The Sage handbook of qualitative research. Sage Publications Ltd., Thousand Oaks, pp 559-603

Liamputtong P (2008) Doing research in a cross-cultural context: methodological and ethical challenges. In: Liamputtong P (ed) Doing cross-cultural research. Social indicators research series, vol 34. Springer, Dordrecht

Merriam SB, Johnson-Bailey J, Lee MY, Kee Y, Ntseane G, Muhamad M (2001) Power and positionality: negotiating insider/outsider status within and across cultures. Int J Lifelong Educ 20(5):405-416

Redwood, S. \& Todres, L. (2006). Exploring the ethical imagination: conversation as practice versus committee as gatekeeper [25 paragraphs]. Forum: Quali Soc Res, 7(2), Art. 34, http://nbn-resolving.de/urn:nbn:de:0114-fqs0602341

Ritchie J, Lewis J, McNaughton Nicholls C, Ormston R (2003) Qualitative research practice: a guide for social science students and researchers. London: SAGE

Roche E, King R, Mohan HM, Gavin B, McNicholas F (2013) Payment of research participants: current practice and policies of Irish research ethics committees. J Med Ethics 39(9):591-593

Schopper D, Dawson A, Upshur R, Ahmad A, Jesani A, Ravinetto R, Dawson A Upshur R, Ahmad A, Jesani A, Ravinetto R, Segelid M, Sheel S, Singh J (2015) Innovations in research ethics governance in humanitarian settings. BMC Med Ethics 16(1):10
Slomka J, McCurdy S, Ratliff EA, Timpson S, Williams ML (2007) Perceptions of financial payment for research participation among African-American drug users in HIV studies. J Gen Intern Med 22(10):1403-1409

Statement of Commitments from Humanitarian Scholars at World Humanitarian Summit (2016) https://ihsa.info/content/uploads/2017/11/CommitmentsWHS.pdf

Titmuss R (2018) The gift relationship (reissue): from human blood to social policy. Policy Press, London

Torre M, Cahill C, Fox M (2015) Participatory action research in social research. In: Wright J (ed) International Encyclopaedia of the Social and Behavioural Sciences. Elsevier, Amsterdam

Van Bavel B, Gilmore B, Wilkinson O (2016) Student guidelines for ethical fieldwork overseas. Development Studies Association and Irish Forum for Global Health, Dublin

Van Duijn, L. \& Hilhorst, D. (2019) 'What has happened with the academic commitments at the WHS?' [Blog post] retrieved from https://www.alnap. org/blogs/what-has-happened-with-the-academic-commitments-at-the-whs

Zutlevics TL (2016) Could providing financial incentives to research participants be ultimately self-defeating? Res Ethics 12(3):137-148

\section{Publisher's Note}

Springer Nature remains neutral with regard to jurisdictional claims in published maps and institutional affiliations.

\section{Submit your manuscript to a SpringerOpen ${ }^{\circ}$ journal and benefit from:}

- Convenient online submission

- Rigorous peer review

- Open access: articles freely available online

High visibility within the field

- Retaining the copyright to your article

Submit your next manuscript at $\boldsymbol{\nabla}$ springeropen.com 